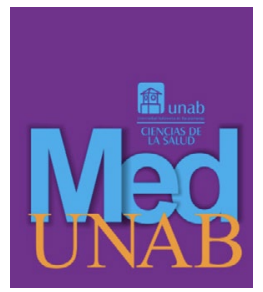

REVISTA DE LA FACULTAD

DE CIENCIAS DE LA SALUD

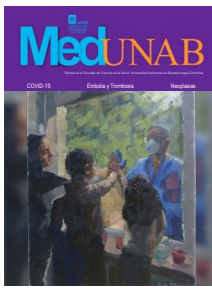

Science and Art

\title{
Dr Salman visiting his family
}

Nick Richards ${ }^{1}$

London Painter

Email: nickslider@gmail.com

Instagram, Twitter: @nickrichardsart

When Dr Salman sent me some reference photos, I instantly knew I had to choose the photo this painting is based on - although it was a complex scene with several figures, the narrative it presented was very powerful and emotional. I wanted to avoid sentimentality, and I think that the bold impasto technique I used, with thick oil paint and a large brush, helped with this. It was mostly about conveying raw emotion in an expressive way, without including lots of detail. Also making it an easily readable image just using loose brushstrokes, without delineating everything was a real challenge. I hope I succeeded.

1. Nick Richards is a London based portrait and plein air painter. He accepts portrait commissions from life or from photos. Nick paints landscapes \& cityscapes directly from life in oils, on location in front of the subject as he loves the challenge of trying to capture the weather, the light and the essence of a place. Nick has exhibited with the Royal Institute of Oil Painters for the last two years, has appeared on Sky Portrait Artist of the Year \& is shortlisted for the Sequested Prize. 